\title{
An evaluation of the World Bank's preparedness to meet future urban transport challenges
}

\author{
P. N. W. Freeman \\ Independent Evaluation Group, World Bank, Washington D.C., USA
}

\begin{abstract}
During 2006 an evaluation was undertaken by the World Bank Independent Evaluation Group (IEG) of the effectiveness of the Bank's global support to the transport sector during the last ten years. This paper focuses specifically on the results of the urban transport component of the study. Troubling issues include environmental damage, energy efficiency, and implications for climate change, traffic congestion, and transport safety, as well as questions relating to affordability and the logistical challenges of effective multimodal transportation. The World Bank has made significant progress in encouraging private sector contracting, especially of maintenance activities, but more modest success with institution building and ensuring infrastructure funding sustainability. However, the time has come to reassess priorities as a new more urban related agenda unfolds.

Keywords: evaluation, urban transport, developing countries, traffic congestion, urbanization, environmental damage, air pollution.
\end{abstract}

\section{Introduction}

Over the next 35 years 2.5 billion people will be added to the current world population of 6.3 billion. In developing countries, much of this growth will be urban and it is expected that there will be 358 cities exceeding 1 million inhabitants by 2015. This expansion, coupled with the impact of ongoing globalization and trade liberalization, is expected to significantly accelerate the demand for transportation.

The motor industry, for example, may have reached maturity in the developed markets of North America, Europe, and Japan, but globally it is poised for a huge expansion, led by the motorization of China and India. Within a few years, China 
will replace Japan as the second-largest national market after the United States; over the next 20 years, unless there are major shifts in the global economy or in technology, more cars may be built than in the 110-year history of the industry.

Today's concerns about high fuel prices will inevitably be heightened. Road transport already accounts for $15 \%$ of the greenhouse gases contributing to climate change. Pollution, noise, ugliness, and wasted time from traffic congestion also impose substantial societal costs. In developing countries the problems of congestion and pollution are further compounded by poor road safety, which has led the World Health Organization (WHO) [1] to declare road safety an international public health issue. Just over a century after the first motor vehiclerelated traffic death in 1896, over 1.2 million people are killed on the roads each year and 50 million more are injured. More than $85 \%$ of these victims are from developing countries and many live in cities.

Public transport offers clear advantages for reducing congestion and pollution and for increasing safety. But progress has often been disappointing, because private vehicle users rarely pay the true costs they impose on society, thus encouraging urban sprawl. At the same time, decentralized cities with lower population densities and long trip distances increase the cost of providing public transport. The urban poor, usually residing on city peripheries, tend to become marginalized by a lack of accessibility. Meanwhile, the rapid growth of megacities is raising concern about worsening air quality, the adverse effects of which fall disproportionately on the poor.

Transport accounts for nearly $6 \%$ of global economy. It is thus hardly surprising that the World Bank (hereafter referred to as "the Bank") has provided more than $\$ 30$ billion, or well over $15 \%$ of its total lending commitments, in support of transport projects during the past decade. The Bank is updating its strategic approach to the sector to address some of the more menacing impacts of global transport expansion and as an input to this initiative, the Independent Evaluation Group (IEG) [2] has assessed the Bank's past contribution to the sector and its readiness to meet emerging challenges.

The Bank's existing transport strategy is founded on three key documents. The World Development Report: Infrastructure for Development [3], which promotes an expanded role for competitive markets in transport. Sustainable Transport [4], which focuses on the need for transport systems to be comprehensively sustained-economically, environmentally, and socially. Finally, Cities on the Move [5] concentrates on the urban aspects of transport. These three elements all remain relevant today but require some adjustment and a different approach to meet the challenges of the coming decade.

\section{Study logic and methodology}

This evaluation was the first comprehensive IEG review of the transport sector; the period covered by the review was July 1995 to June 2006, during which time there were 642 projects with transport components in the portfolio. Of these, 335 had been closed and 284 evaluated, so the size of the database is substantial. Nearly $80 \%$ of these projects relate to roads, representing commitments of $\$ 25$ billion over the decade. Several instruments were used in the evaluation: 
Literature review: This covered published documents on transport issues relating to developing countries, complemented by a review of Bank non-lending transport activities.

Portfolio review: This extensive customized database provided the foundation for an analysis of how the projects performed, their outcomes, and what lessons have been learned.

Analysis of existing evaluations: Comprised 57 Country Assistance Evaluations, 254 reviews of Implementation Completion Reports (self evaluations), and 74 Project Performance Assessment Reports (detailed audits), covering 41 countries. The latter were usually carried out between two and four years after a project had closed and were in-depth evaluations involving site visits and discussions with government officials, user groups and relevant stakeholders.

Special thematic studies: These included papers on road funds and a global overview of public/private sector issues in transport.

Stakeholder interviews and Bank staff interviews: One-third of the Bank's transport network staff was interviewed. Stakeholders included government officials, providers of transport services, and interested parties such as consultants, user groups, and academics.

\section{The urban environment}

An IEG evaluation of environmental sustainability in development [6] noted that many developing countries view international concern over environmental problems in their countries as intrusive and likely to impede development. Their governments argue that developed countries have overexploited the environment, refused to take full responsibility for mitigation of their own impacts, and now want to shift that responsibility to developing countries without adequate compensation. This perception has substantial validity and has complicated the role of the Bank. At the same time, public tolerance for inadequate compliance by the Bank of its own policies is low.

Issues such as air pollution have gained importance in recent years. In Dhaka, Bangladesh, highly polluting three-wheeled taxis with two-stroke engines were removed under the Bank's Air Quality Management Project. This made a significant difference to air pollution. Similar measures to cope with twowheeled traffic are needed in many other Asian countries such as Thailand and Vietnam. But only six Bank projects related to the urban environment and air quality in 10 years have been completed and evaluated. One of these was a Transport Air Quality Management Project for the Mexico City metropolitan area. The project, which was rated as satisfactory, led to a significant decrease in the ambient concentrations of pollutants. It also resulted in fewer respiratory illnesses and other acute syndromes of poor quality air. More of these projects are needed.

A seminal Bank publication on the air pollution issue, Reducing Air Pollution from Urban Transport [7], provides a practical framework of guidelines and principles on how to select appropriate policies and take mitigation measures against the worsening poor urban air quality. The WHO in 2000 estimated that 
650,000 people die prematurely from urban air pollution in developing countries. But Bank involvement is still small and arguably should be much greater, especially in Asia. The adverse effects of air pollution fall disproportionately on the poor, compounding other environmental problems such as lack of clean water and sanitation. Transport energy conservation is another area increasingly being given prominence; in Brazil more than a third of the country's cars run on either pure ethanol or gasoline-ethanol blends. Natural gas to power public transportation is becoming more common, and many cities have programs to eliminate leaded gasoline.

\section{Urban planning, design and management}

Urban planning programs that integrate public transport, land use, and air quality strategies have been promoted for many years. Curitiba, Brazil, and Bogota, Colombia, where people's mobility has been supported through use of public transport, have long been recognized as instructive models for urban planners, but such achievements resulted from unusually forceful leadership. The Bank has shown that extending and modernizing commuter rail systems and bus corridors is an effective way to alleviate heavy urban traffic congestion (Brazil). Attention is also increasingly being given to the installation of centralized traffic management systems (Bangladesh and Vietnam) to regulate traffic flows as efficiently as possible. Parking strategies can improve traffic flow, generate revenue, and discourage car usage. In a few cities special arrangements have been made for non-motorized transport (Bangladesh and Philippines), but this is an area where much more research is needed.

Whether and how transport can influence behavioral change in established industries and by consumers to meaningfully address climate change trends remains an open question. Given the expected growth in the vehicle population, the demand for road space by private vehicles will inevitably have to be constrained through pricing mechanisms and physical restrictions. Several solutions are already technically possible, but the extent to which measures that constrain vehicular use will be supported politically is uncertain, given their likely unpopularity with the public. Europe is moving in the right direction, but the United States and most of the developing world is lagging. This is a longterm problem to which the Bank will need to devote more serious attention and even advocacy given that there is no United Nations entity exclusively focused on transport issues.

Much of the growth in the world's population for the foreseeable future will take place in the cities and towns of the developing world. In 2000 the world's urban population in developing country cities reached 2.1 billion; it is expected to grow to at least 2.9 billion by 2015 . By 2025 more than half of the world's population will live in urban or peri-urban areas and 600 million people are expected to migrate from rural areas to cities in the next ten years. To put this in perspective, this urbanization trend is equivalent to 60 additional cities roughly the size of London or Moscow. Although the benefits that urbanization brings are potentially huge, the speed and scale of this transformation presents many 
challenges. Urban transport projects supported by the Bank have covered construction or rehabilitation of urban roads, bridges, and interchanges; improvements to traffic management and systems; and (in a few cases) support to suburban rail transport and renewal of bus and trolley-bus fleets.

Bank emphasis has often been on encouraging the design of urban transport projects to improve the integration between services and to increase the access of the urban poor to employment and health centres, and educational facilities. A new contingent of policymakers is assuming the diverse responsibilities of urban governance - as many national governments decentralize and devolve their functions; and programs in poverty, health, education, and public services are increasingly being placed in the hands of hitherto untested municipal and regional governments.

Many of the Latin American Bank financed urban transport projects based on urban railway restructuring or public transport reform have also been de facto instruments to catalyze broader institutional reform, such as the creation of metropolitan authorities, modal coordination, resource generation for the development of activity poles, and the private concessioning of operations. In some Brazilian cities improvements in access to metro stations through introducing connecting minibus service lines with subsidized fares have proved successful. However, poor people may live too far away from such public transport corridors to benefit from these projects. This is also an international problem because the urban poor, whether in Moscow, Paris, or Johannesburg, tend to live on the city peripheries where land is cheaper, but where travel distances are longer, more costly, and less convenient.

Some of the early projects that included components on bus deregulation and privatization proved unsustainable (Sri Lanka), and in recent years the Bank has resisted bus replacement, unless accompanied by significant regulatory reforms to achieve longer-term sustainability (for example, Uzbekistan and Kyrgz Republic) — a strategy validated by project performance. Moreover, the Bank has discouraged the use of development loans and credits for metro and light rail construction worldwide (with a few exceptions in megacities) in favor of more cost-effective solutions such as buses, bus priority measures, and exclusive busways. It has, however, supported improving the capacity (South Korea) or connectivity (Brazil) of existing metros. Competitive contracting has also been actively encouraged.

Pro-poor fare pricing with targeted subsidies, such as the vale transporte, has been successfully promoted in Brazil, where it is an important social safety net (this subsidy is a compulsory requirement for employers and is used to finance part of the commuting costs of their employees). Without the vale transporte, millions of formally employed users earning $\$ 300$ per month or less would have trouble paying their fares. However, the vale transporte does miss the poorest people, and a future challenge is how to extend benefits to the informal sector.

\section{Results and trends}

Bank projects featuring private sector concessions have not grown substantially during the past decade. Clients generally turn to the Bank Group either for 
advice or when the investment is perceived as risky. However, where the Bank has supported or facilitated concessions, they have usually been rated satisfactory or better.

For the foreseeable future, however, the public sector in developing countries will continue to be the major owner and operator of basic transport infrastructure. This is in part because the sector is dominated by roads, which have public good characteristics. The Bank increased its commitments for public sector transport projects once it realized that insufficient private sector investment would be forthcoming.

But the Bank's most important contribution to involving the private sector has been not in outright privatization, but through the many programs in which it has encouraged performance based private contracting. Also influential has been the abolition of departmental construction and maintenance units, support for road agencies and/or funds, and its insistence on competitive bidding for contracts. For railways, many governments are not prepared to agree to long-term concessions. Nevertheless it has still proved possible to improve accountability and transparency in financing arrangements, including more openness about subsidization arrangements for non-economic services, and a greater willingness to divest non-core business components.

The Bank has generally had a mixed performance in helping to strengthen client institutions, with mostly modest results in low-income countries where governance is weak, but better results in middle-income countries. Training too has often been aimed at assisting the immediate project and thus less likely to have any broader or sustained impact. Sometimes, the timing of training interventions has not been synchronized with the organizational changes needed to improve public sector performance. Institutional change takes time, and the duration of the project intervention is usually relatively short. Institutional objectives need to be more realistic and pursued incrementally through a continuing support program that extends beyond the transport sector itself.

In a 2003 IEG evaluation summary of urban transport some 30 Bank interventions in urban transport over the preceding 20 years were reviewed; $87 \%$ were found to have had satisfactory outcomes. The re-estimated average economic rate of return was found to be $30 \%$, compared with $43 \%$ at appraisal, which shows a degree of over-optimism in preparation. These results are slightly higher than those covered by the current study (1995-2006), in which $75 \%$ had a moderately satisfactory or better outcome.

An inspection of the complexity of the objectives shows, however, that later projects have had more institutional content. In terms of upgrading physical infrastructure, most projects achieved or even surpassed their physical objectives, while traffic management programs were more successful in countries with the ability to enforce traffic regulations, such as Brazil and South Korea. Projects that tried to bring about better integrated development, such as in the cities of Belo Horizonte and Recife, sometimes took longer than expected to implement because of exogenous factors (Brazil imposed severe fiscal constraints after 2002 following the macroeconomic upheaval in Argentina). 
Sustainability was considered likely, however, in more than two-thirds of all urban transport projects assessed.

Although a few projects have tackled the issue of integrating non-motorized traffic and pedestrians in cities, this can be a difficult challenge because the incumbent professionals have often been trained in western countries and follow developed country philosophies toward the control of transport in developing cities. Sometimes, as Tiwari indicates [8] a change in locally accepted notions of appropriate city planning is warranted. Non-motorized transport projects are still comparatively rare given the huge numbers of non-motorized transport users. Current estimates show, for instance, that there are 1.4 billion bicycle users worldwide, including 500 million in China.

Considering the current huge growth in developing cities (in East Asia $70 \%$ of regional economic growth) the number of urban transport projects supported by the Bank appears comparatively low. Over the fiscal 1996-2005 period, such projects have only accounted for between $5 \%$ and $8 \%$ of the transport portfolio and appeared to be declining slightly rather than increasing, as might have been expected. IEG contends that this is partly due to insufficient capacity and/or priority in the Bank's transport network and sometimes an aversion to taking on too many large, complex projects that require lengthy preparation time. Given the successful outcome results reported above, the longer preparation time with more consultation does appear to produce more positive project outcomes.

Table 1: Distribution of urban projects and components, closed and active (1995-2005).

\begin{tabular}{lccc}
\hline & $\mathbf{1 9 9 5 - 2 0 0 0}$ & $\mathbf{2 0 0 1 - 0 6}$ & $\mathbf{1 9 9 5 - 2 0 0 6}$ \\
\hline Total number of urban projects & 41 & 37 & 78 \\
Number of project components: & $\mathbf{7 8}$ & $\mathbf{7 7}$ & $\mathbf{1 5 5}$ \\
Urban roads & 27 & 24 & 51 \\
Traffic management and safety & 10 & 9 & 19 \\
Institutional, regulatory, planning & 12 & 19 & 31 \\
Non motorized, urban poor & 7 & 7 & 14 \\
Urban environment, air quality & 3 & 3 & 6 \\
Public transport & 19 & 15 & 34 \\
\hline
\end{tabular}

When staff interviewees were asked what in their opinion constrained the sector from undertaking more urban transport projects, the response was invariably the time taken to prepare projects in a complex environment in which there were multiple stakeholders as well as relocation, environmental and safeguard issues.

The recent referral of the Mumbai Urban Transport Project in India to an "Inspection Panel" was cited as an example of the hazards of increasing complexity. However, the results of the work on resettlement in Mumbai may prove in time to be more valuable than the physical outcome of the project. Some 
staff indicated that there was no internal incentive for them to get involved in more difficult, time-consuming, and risky projects; indeed, the nature of complex projects with many safeguard issues acted to discourage task team leaders. Others said there was a tacit understanding in some countries that because the Bank's processes were "elaborate", other financiers might be preferred for urban projects. The main risk of undertaking more complex projects is that because of longer preparation time, fewer projects overall will be completed with the same resources. There is already a clear trend towards larger projects to compensate to some extent for this. It is also possible that the number of successful projects will decline because there are more factors that can go wrong and more stakeholders to be satisfied. Nevertheless, the world is inexorably becoming more complicated, and this means that the Bank must prepare itself to meet such complexities head on and take more risks.

\section{The way forward}

The Bank's existing transport strategy, with its focus on sustainability, urban transport, and the encouragement of greater private sector involvement, remains broadly valid. But clean, affordable, and safe transportation is the important challenge for the coming years.

The greater emphasis on safety also supports the Millennium Development Goals addressing health issues. It is predicted that by 2020 road accidents will become the third-largest contributor to the global burden of mortality and injury. Bank-financed projects until recently have rarely tackled road safety holistically, but there is evidence that new programmatic road safety approaches are more effective.

The Stern Report [9] shows that air quality has assumed new importance with the growing number of motor vehicles contributing to the volume of greenhouse gas emissions. This is a powerful reason to increase support to urban transport; it provides opportunities not only to reduce air pollution and other environmental damage, but also to explore ways to reduce the long-term energy demand through traffic management and pricing, constraints on the use of private cars, and greater support for mass transit systems and public transport in general. London has successfully introduced a central city access charge, while Austria, Germany, and Switzerland have created electronic systems to charge trucks for the costs that they impose on the roads. Such advances in technology are expected to spread at least to some middle-income countries in the near future, but low income countries will need simpler and less sophisticated solutions and more focus on affordability.

The Bank has already discovered that it can obtain greater leverage from sources of funding such as the Global Environment Facility and the United Nations Environment Program. Carbon finance initiatives in future years also have the potential to fund global research projects. The UN Environment Program recently launched a multimillion dollar public transport project covering three polluted cities in Latin America. In Europe an emissions trading scheme, which imposes carbon dioxide emission limits on factories and power 
stations, has been introduced as the mainstay to meet its Kyoto Protocol goals. Transport will be included in 2013.

The rapidly increasing interaction between transport and other sectors is an important matter; there is no doubt that transport is developing into a complex multisectoral business. But it is not yet clear whether the present deployment of Bank resources will be sufficient to meet its share of these additional sector challenges as well. It appears to IEG unlikely that these new priorities can be achieved meaningfully without either scaling up support or reassessing sector priorities and engaging in greater dialogue with borrowers. This will require working across sectors through multisectoral teams and will generate increasing complexity. An additional factor to consider is the pace of change in the business environment. For example, in the coming decade many Asian countries will attain middle-income country status, effectively changing the nature of the demand for Bank services.

Another potential growth area includes introducing sub national lending through a new facility (subject to the caveat that some national governments are worried about sub national debt sustainability). Capacity at the sub national level varies considerably. For example, in the Middle East and North Africa, few cities would contemplate taking on additional debt. However, in other cases there is a great opportunity because the Bank's comparative advantage lies in helping build capacity at sub national level in support of national governments. This strength is expected to leverage additional finance for infrastructure.

The new priorities will require greater focus as well as more innovation and experimentation to ensure continued Bank relevance. A particularly big challenge will be to find low cost solutions for poor countries. Typical measures such as better traffic management have hidden costs in upgrading the level of law enforcement. Overall, the sector is at a crossroads, but it does have a window of opportunity to attain a higher level of relevance and offer a better level of support to its clients.

\section{References}

[1] World Health Organization World Report on Road Traffic Injury Protection. Geneva 2004

[2] World Bank, Independent Evaluation Group A Decade of Action in Transport: An Evaluation of World Bank Assistance to the Transport Sector, 1995-2005 Washington DC, 2007

[3] World Bank World Development Report: Infrastructure for Development Washington DC 1994

[4] World Bank Sustainable Transport: Priorities for Policy Reform Washington DC 1996

[5] World Bank Cities on the Move: A World Bank Urban Transport Strategy Review Washington DC 2002

[6] World Bank Independent Evaluation Group Promoting Environmental Sustainability in Development: An Evaluation of the World Bank's Performance Washington DC 2002 
644 Urban Transport XIII: Urban Transport and the Environment in the 21st Century

[7] World Bank Reducing Air Pollution from Urban Transport Washington DC 2004

[8] Tiwari, G. Low Cost Means of Transport in Cities: The Critical Element in the City Transport System in Low Income Countries CODATU Conference on Urban Mobility for All; Lomé 2002

[9] Stern, N. The Economics of Climate Change HM Treasury London 2006 